\title{
A Framework of E-learning System for Students' Engagement with Cognitive Tasks to Enhance Learning Performance
}

\author{
Agbonifo, Oluwatoyin Catherine \\ Department of Computer Science \\ Federal University of Technology, Akure, Nigeria
}

\author{
Adewale, Olumide Sunday \\ Department of Computer Science \\ Federal University of Technology, Akure, Nigeria
}

\begin{abstract}
The use of integrating technology with learning has been a pivot that transformed the role of instructors and students; and makes it both technology-driven and learner-centric controlmediated. It has been a research-based issue in connecting technology and learning theories for effective learning performance. Learning should be a platform where students are actively engaged in a process to construct a realistic and meaningful knowledge suitable to solve an impressing and confronting societal problems for sustainable development. The approach to learning has been in diverse ways from the fundamental principles of learning theories and strategies. The emphasis of learning is in making it a platform where students can be attracted to it to study effectively, for easy retention and recall and able to apply the knowledge acquisition to futuristic similar real-world problems. Many researchers have worked along with this school of thought; all is to enhance study performance of students. Hence, the research paper develops a framework of e-learning system that engages students in active cognitive tasks to enhance their learning performance.
\end{abstract}

\section{General Terms}

E-learning Technology, Cognitive Information Processing

Keywords

Technology-driven, cognitive tasks, learning theories, learning performance

\section{INTRODUCTION}

E-learning technology has been defined by many researchers depending on the basis in which learning has been designed and applied for. E-learning is defined in this paper as "the use of Internet technologies to create and deliver a rich learning environment that includes a broad array of instruction and information resources and solutions, the goal of which is to enhance individual knowledge and organizational performance"[17]. The use of information technology has actually influenced educational settings from the traditional perspective to technology-mediated of teaching and learning environment. Many other parameters have been considered in e-learning concept to enhance student learning performance. The relevance of an individual's cognitive style and learning style to that person's performance in a range of learning situations has been explored by many researchers over the years [10] [13] [11] [15][16]. The issues of personalization, stimulating learning study, learning strategy and tasks have been extensively carried out as a research by various researchers in the fields of education and psychology with encouraging research findings output to improve online learning performance. Various technological devices to mediate these stimulating parameters in learning and teaching in these fields have also been explored and developed. According to [18] motioned that some web 2.0 applications are effective at increasing satisfaction with a course, improving their learning and their writing ability in educational contexts, and increasing teachers' interaction with students.

The emergence of advanced technology such as Internet and the World Wide Web has hosted electronic interaction between a myriad of learners across the planet, facilitating the learning process for all participants [3]. According to [4] carried out a study plan to examine the intention of students through a survey of sample of undergraduates on the use of developed self-learning technological application which is to complement the existing teaching and learning methods related to memory management operations, the evaluation survey through the study showed students' attitudes towards using this application in their learning is judged essential. There are a lot of digital mediated learning applications such as university ePortfolio developed in [6] which was used to analyze the students' experiences and reflections towards the use of ePortfolio in tracking students' learning outcomes within the courses to observe their academic growth and prepare them for future careers. The collection of data which is both qualitative and quantitative on students' use of ePortfolio revealed students' reflective growth, selfknowledge, network and social skills.

According to [22] proposed adaptive hypermedia technology to improve learning process by adapting course content presentation to student learning styles. The results showed that students taught using learning style adaptive system performed significantly better in academic achievement than students taught the same material without adaptation to learning style. The projection in e-learning development by the instructional designers is to ensure that it provokes or stimulates contextual process and practices on the part of learners rather than outcome and standard. Hence, this paper emphases the framework of e-learning system that engages students with active cognitive tasks in enhancing learning performance.

\section{E-LEARNING AND LEARNING TASKS}

Most e-learning applications have their instructional materials separated from the learning tasks which violate the principles of learning theories that says "testing should be integrated with task as a single activity and not a separate activity [1]. 
Most of e-learning applications are used in form of blended learning, the instructional content is delivered in a face-toface classroom and the assessment to evaluate the level of students' knowledge is mediated through technological process. Fragmentation in the online course development causes the experience of education to easily fade away; the understanding of the structures of the technologies to use is an important issue that can resolve this [9]. In online course development, learning environment should be mediated to subject learners to cognitive learning tasks that would promote critical thinking, mental skill, and high rate of attention, retention and recall.

The learning activity should be closely aligned with the learning objectives of the course and should promote higher order of critical [20. Learning tasks can also be termed as assessment of learning that describe those strategies designed to confirm the level of students' understanding of certain concepts at a particular moment in time [8]. There are various technological-mediated devices improvised to facilitate the outcome of learning objectives such as touch-screen inputbased over mouse-padded device [14]

\section{RELATED WORKS}

The essential component of learning is that man should increase in knowledge and skills which serve as a pool to knowledge society and sustainable economic strength of any nation. Education is the pivot that opens up these unprecedented opportunities. The use of Information technologies in transforming the world of education from grass to grace has been the new innovations to this panacea. Technologies have made teaching and learning to be much easier in terms of processing, wide coverage of target audience in course delivery, assimilation, accommodation, the use of higher order of cognitive strategies and skills, retention and recall. It is much easier in using computer technology to mediate learning environment because of the similarity between the way man processes information using the Godgiven gift of brain, neural cells and other circuitry connection which relate to human memory processing units; and computer information processing system.

Learning environment is rapidly changing due to exponential growth rate in development of Internet and Information Technologies. According to [19] developed a personalized remedial learning system to assist learners in remedial learning after an online assessment. The system adopted the fuzzy logic theory to construct an appropriate learning path based on learner preference. The outcome of learners' achievement confirmed that the system was suitable for the underlined objectives. According to [5] carried out a study which was intended to measure the effectiveness of the emerging skill and problem solving with technology in the contemporary of National Assessment of Education Progress (NAEP). In the paper, the assessment scenarios were administered to nationally representative samples of 8th-grade students in over 200 schools. The outcome of the analysis showed that using online assessment has a great positive impact on the performance of the students.
Furthermore, according to [7] investigated with the use of ongoing research project named Semantic-WikiSUN, the innovative strategies for learning and teaching Computer Science in the context of higher education. The use of semantic-wiki is to support sharing and acquiring of knowledge in the specific knowledge domain and enabling the application of basic pedagogical principle. According to [21] developed an adaptive learning system with multiple perspectives based on students' learning styles and cognitive styles. The researchers set up an experimental group and control group. The experimental group learned with an adaptive learning system developed while control group learned with the conventional learning system without personalized presentation. The outcome of the study showed that experimental group students revealed significant better learning achievement than control group students. According to [12] developed a computer assisted mathematical problemsolving system which forms a network instruction website to help low-achieving second and third graders in mathematics.

\section{OVERVIEW OF HUMAN MEMORY PROCESSING MEMORY}

Human cognitive architecture as shown in Figure 1 was defined in [2] as the way cognitive structures are organized and interrelated. Information is received by the learner through senses or external stimulus which involved a number of cognitive learning processes that lead to the actual response to that stimulus. Information is received by receptors for temporary storage via sensory cells and stored in the sensory memory. Sensory information is stored in the human brain at closely linked neuronal cells. The sensory memory is a large capacity storage that can save information with high accuracy. This type of memory decays at a fast rate to keep provisions for entry of new information. In the sensory memory, the information can be forgotten or initially processed into shortterm memory (STM). Information in these cells can be preserved only for a short duration. Short-term memory also referred to as active or working memory is the momentary storage of information that is processed to perform cognitive tasks; information at this stage can be forgotten or elaborated and coded into long-term memory (LTM). Those cells in the long-term memory can hold information for a quite long time in the order of years. LTM can also be referred to as where previously learned and stored information is processed which is related to other cognitive abilities such as problem solving. Humans can only use the contents of LTM when it enters short-term memory through retrieval.

In [1], a clear distinct analogy was drawn between the human cognitive memory model and the memory systems in computers. The STM is similar to cache, while the LTM could be compared with main memory. The reasoning system in the human brain is analogous to the central processing unit (CPU) of the computer. The reasoning system fetches information from the STM, as CPU receives information from cache, when the addressed words are available in the cache. In case the addressed words are not available in STM, such words could be transferred from the LTM to the STM and then to the reasoning system. 


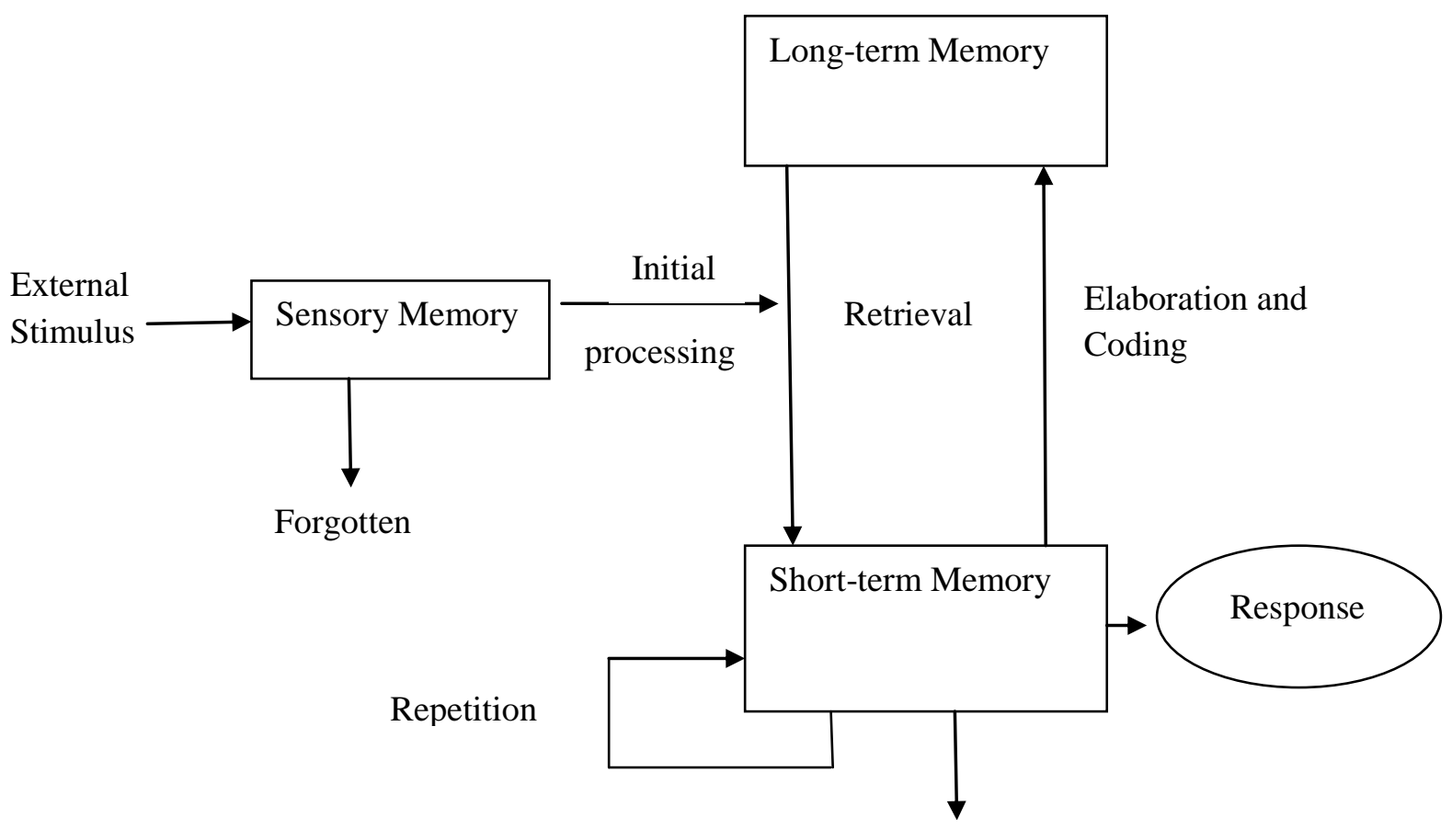

Forgotten

Figure 1: Human Memory Processing Model [2]

\section{SYSTEM DESIGN}

This section presents the architecture and modeling components of the e-learning system.

\subsection{System Architecture}

The architectural design of the system is depicted in Figure 1 showing a technological mediated learning environment that enables students to achieve cognitive activities. The architecture is situated on three tier client-server technology which has formal description of various components such as presentation layer, application layer and database layer. The relative description of these components to this work is that the presentation layer e.g. user interface is responsible for displaying information that would require the users to supply personal information and to access the sequence of learning units and tasks.

The application layer uses scripting language and is responsible to process various request commands made through the client side to the server side and vice versa. The various request commands are the creation of learning objects as regards to user personal information, hypermedia learning contents into various chunks of learning units and tasks, and capturing of user cognitive activities as engaged in learning process (learning units and tasks). The educational material is sequenced into various chunks of learning units and tasks with respect to definite goals and objectives of the learning concepts.

The database layer is responsible for the management of information that flows between the user interface into the database and vice versa. The various information flows which are stored in the database are user personal information, the structure and the digital content of the educational materials that represents the learning units and learning tasks (exampled-based and problem-based solving tasks); and user interaction with the learning units and tasks that is mediated as user cognitive activities such as visual attention, goal relevant information, recall and retention The learning environment is mediated with cognitive activities to determine the level of students' knowledge as relate to specific domain knowledge. 


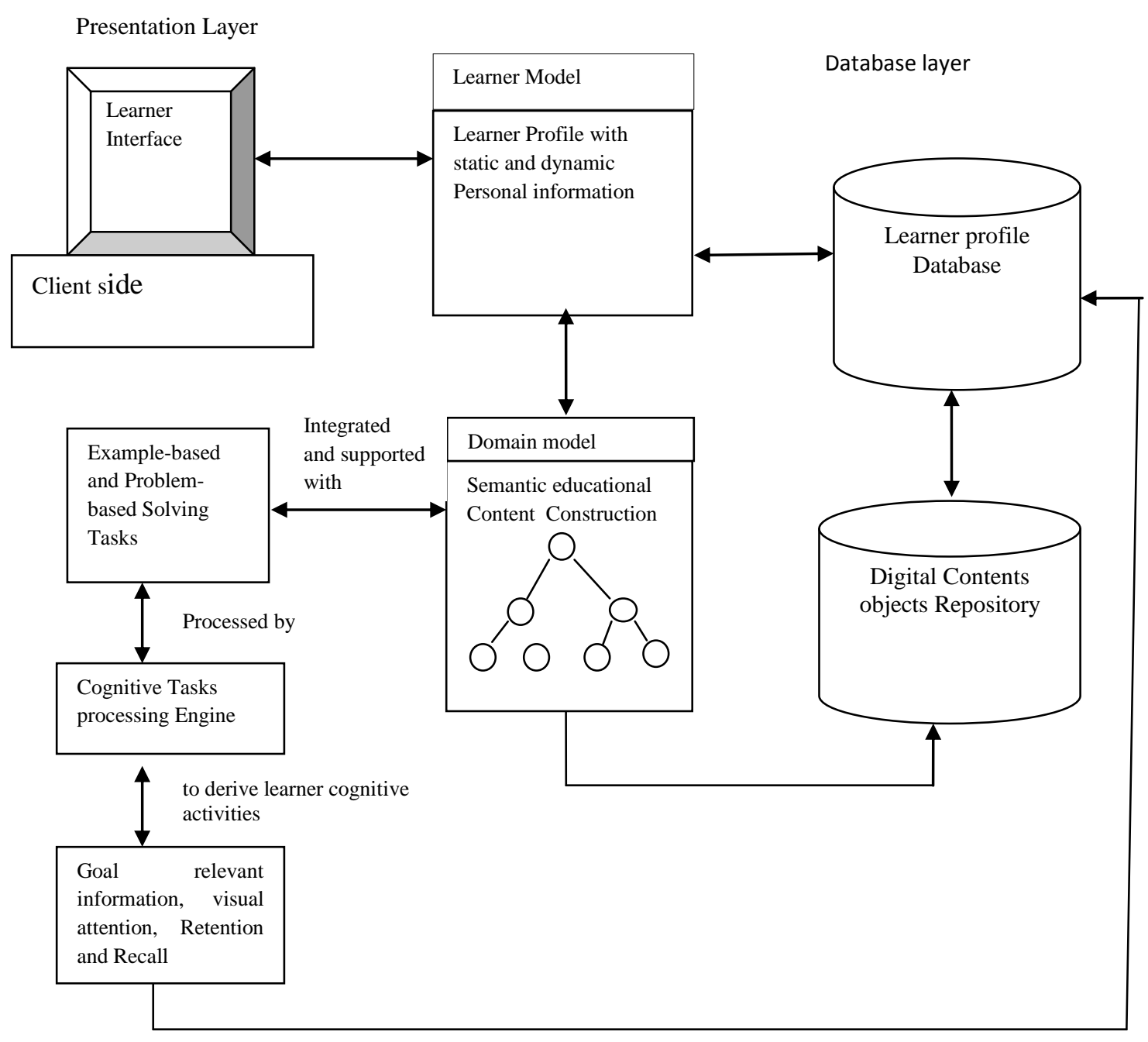

Figure 2: System Architecture of E-learning System Synchronized with Cognitive Tasks

\subsection{Modeling Phase}

This section describes the modeling components of the system architecture.

\subsubsection{Learner Modeling}

This is one of the components in e-learning development environment and there is a need to ensure that learners' requirements are satisfied. This is mostly achieved by knowing the learner profile which contains relevant information about the learners that are using the e-learning environments. In this design, the learner' information consists of static information such as learner identification, faculty/school name, field of study/course, age, learner' interests; and dynamic information is those information that changes within certain period of time such as the cognitive activities which are obtained as a result of learner interaction or engagement during learning process. The cognitive activities parameters are; goal relevant information, visual attention, retention and recall. Goal-relevant information is inferred from learners' interaction with the system as it relates to learner knowledge to the definition of the learning objectives of the course or concepts. Visual attention is obtained when the learner attention at the time of studying is focused more on informative knowledge concepts and it is confirmed in the strength of learner's learning performance in the usage of these concepts during problem-solving process. Retention and Recall refer to the ability of a learner in a given problem domain as $s /$ he is able to understand the concepts presented in learning process and use the understanding to solve other problems of similar contexts.

\subsubsection{Domain Modeling}

Learning objects with respect to knowledge concepts in curriculum sequencing are set of concepts that forms network concepts and have link or associative relationship between one another. These concepts must be learned by learner and the level of their comprehension and knowledge acquisition must also be determined by various cognitive tasks associated with the learning process. For example, a course is to be disassembled into different chunks of learning units using curriculum/syllabus authoring process and modeled using 
learning objects of metadata scheme. Let $C_{i}$ be the course to be learned by the learner and let $T_{k} \subseteq C_{i}$ and $S_{k l} \subseteq T_{k}$ where $\mathrm{k}, 1=1,2,3$, represent several topics and subtopics to cover in the curriculum. The page $p_{k}$ of $T_{k}$ and $S_{k l}$ also denotes the concepts presented to the learners to learn to attain the level of mastering. Several learning tasks which referred to cognitive tasks parameters such as goal-relevant information, visual attention, retention and recall are associated with the learning process. These tasks are modeled as described in the following subheadings:

i. Goal-relevant information: When the learning objectives of a given curriculum are defined and the network of knowledge concepts are organized to reduce cognitive load effects and to attract attention on goal-related and relevant knowledge concepts. Then, the involvement of cognitive processes must be that there is a low amount of learner' mental activity that short-term memory must deal with simultaneously and which must be transferred to long-term memory.

ii. Visual attention: This tasks is conceptualized using the empirically validated assumption made in [23] that when a person is performing a cognitive task in the context of watching a display, the location where the learner is gazing on corresponds to the symbol currently being processed in working memory. The eye naturally focuses on areas that are most likely to be informative. If a given problem domain can be solved by the learner and matched with problem solution within a certain period of time without necessary revisiting the pages of the concepts at the instance of solving, then it can be said that visual attention has been given to the knowledge concepts at the time of studying. Model of Visual Attention addresses the learners' perception in the user's attentional visual field and involves a number of cognitive learning processes that lead to the actual response to that stimulus which can be referred to as visual attentive behaviour.

iii. Retention and Recall: Given a network of knowledge concepts $K C_{i} \ldots K C_{n}$ through which a problem domain $P b_{k}$ must be solved using the network of knowledge concepts. A learner must apply these knowledge concepts appropriately to solve the given problem which matches within the steps process of problem solution space, then learner' ability in retention and recall can be measured.

\subsubsection{Evaluation Model}

The evaluation model uses the following linguistic terms with associated range of numerical values as grade points as described in Table 1.

Table 1: Linguistic Terms with associated Range of Numerical Values for Evaluation

\begin{tabular}{|l|l|l|}
\hline Cognitive Tasks & $\begin{array}{l}\text { Linguistic } \\
\text { Terms }\end{array}$ & $\begin{array}{l}\text { Range of Numerical } \\
\text { values (points) }\end{array}$ \\
\hline $\begin{array}{l}\text { Goal-relevant } \\
\text { Information }\end{array}$ & not used & $0-3$ \\
\cline { 2 - 3 } & moderately used & $4-6$ \\
\cline { 2 - 3 } & well used & $7-10$ \\
\hline Visual attention & $\begin{array}{l}\text { not fixed on } \\
\text { goal related } \\
\text { information }\end{array}$ & $0-3$ \\
\hline & $\begin{array}{l}\text { moderately } \\
\text { fixed }\end{array}$ & $4-6$ \\
\hline
\end{tabular}

\begin{tabular}{|l|l|l|}
\hline \multirow{2}{*}{} & $\begin{array}{l}\text { fixed on goal } \\
\text { related } \\
\text { information }\end{array}$ & $7-10$ \\
\hline Retention & low & $0-3$ \\
\cline { 2 - 3 } & moderate & - \\
\cline { 2 - 3 } & High & $7-10$ \\
\hline Recall & $\begin{array}{l}\text { not apply } \\
\text { concepts on } \\
\text { similar problems }\end{array}$ & $0-3$ \\
\cline { 2 - 3 } & $\begin{array}{l}\text { moderately } \\
\text { apply }\end{array}$ & $4-6$ \\
\cline { 2 - 3 } & $\begin{array}{l}\text { apply concepts } \\
\text { on similar } \\
\text { problems }\end{array}$ & $7-10$ \\
\hline
\end{tabular}

\section{RESULT AND DISCUSSION}

In the simulated model, "Introduction to Java programming language" was used as the teaching material. This particular study material is disassembled into fine-grained chunks of learning units and tasks; alongside with associated learning goals and objectives in hypermedia pages as knowledge concepts. There were set of problem-solving questions associated with underlined domain knowledge concepts. The sample of five learners that actively engaged with the learning process and their learning outcome is shown in Table 2 and the graphical representation in Figure 3. The learning outcome demonstrates progressive learning study and action performed on various tasks on the part of learners that promotes mental ability.

Table 2: Learners' Learning Outcome on Cognitive Tasks

\begin{tabular}{|l|l|l|}
\hline Identification & Cognitive tasks & Grade point \\
\hline Learner01 & Goal-relevant information & 10 \\
& & \\
\cline { 2 - 3 } & Visual attention & 7 \\
\cline { 2 - 3 } & Retention & 8 \\
\cline { 2 - 3 } & Recall & 8 \\
\hline Learner02 & Goal-relevant information & 9 \\
\cline { 2 - 3 } & Visual attention & 6 \\
\cline { 2 - 3 } & Retention & 7 \\
\cline { 2 - 3 } & Recall & 7 \\
\hline Learner03 & Goal-relevant information & 9 \\
\cline { 2 - 3 } & Visual attention & 8 \\
\cline { 2 - 3 } & Retention & 8 \\
\cline { 2 - 3 } & Recall & 8 \\
\hline Learner04 & Goal-relevant information & 6 \\
\cline { 2 - 3 } & Visual attention & 4 \\
\cline { 2 - 3 } & Retention & 5 \\
\cline { 2 - 3 } & Recall & 5 \\
\hline Learner05 & Goal-relevant information & 5 \\
\cline { 2 - 3 } & Visual attention & 4 \\
\cline { 2 - 3 } & Retention & 6 \\
\cline { 2 - 3 } & Recall & 5 \\
\hline
\end{tabular}




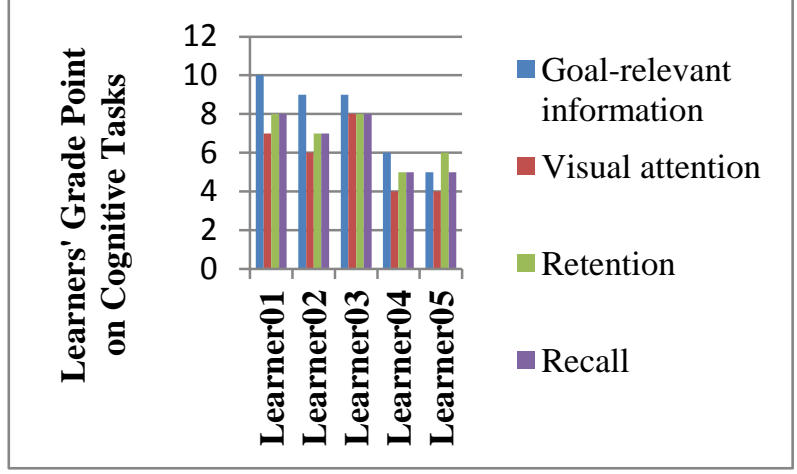

Figure 3: Learners' Learning Outcome on Cognitive Tasks

\section{CONCLUSION AND FUTURE DIRECTION}

In the development of e-learning environment, consideration must be given to the following factors such as the definition of the learning objectives which must be supported with instructional strategies; and methods to achieve the objectives in order to promote learner learning performance. In this paper, learning is technological mediated to take the advantage of user's centre control that is also supported with instructional resources that would enable learners to engage in cognitive activities that promote skill acquisition and mental reform in the knowledge domain. The simulated model should be developed to a fully implemented system that would be deployable for use in any educational settings.

\section{REFERENCES}

[1] Agbonifo, O. C. 2012. Design of a Neurofuzzy-Based Model for Active and Collaborative Online Learning. Ph.D Thesis submitted in the Department of Computer Science, Federal University of Technology, Akure, Nigeria, pp 1-176.

[2] Alasraj, A., Freeman, M. and. Chandler, P. A. 2013. Considering cognitive load theory within e-Learning environments. Proceedings of the Asia Conference on Information Systems (PACIS) pp. 1-13.

[3] Amy, S. C. L. and John, M. 2013. Use of Telecommunications Technologies for Online Community and Distance Learning,. In Jan Herrington et al. (Eds.), Proceedings of World Conference on Educational Multimedia, Hypermedia and Telecommunications pp. 461-464.

[4] Aristogiannis, G. 2011. Design and Development of a Web-based Interactive Software Tool for Teaching Operating Systems. Journal of Information Technology Education Volume 10, pp. 1-17.

[5] Bennett, R. E., Persky, H., Weiss, A. and Jenkins, F. 2010. Measuring Problem Solving with Technology: A Demonstration Study for NAEP. Journal of Technology, Learning, and Assessment, 8(8), pp. 1-45, ISSN 15402525, Available at: http://www.jtla.org.

[6] ChanLin, L. and Chou, T. 2013. Eportfolio for Learning and Reflective Growth. In Jan Herrington et al. (Eds.), Proceedings of World Conference on Educational Multimedia, Hypermedia and Telecommunications $p p$. 25-32.
[7] Coccoli, M., Vercelli, G. and Vivanet, G. 2013. Semantic wiki for learning and teaching computer science. Journal of e-Learning and Knowledge Society, vol.9, No. 2, 169-179.

[8] Code, J. and Zap, N. 2013. Assessments for Learning, of Learning, and as Learning in 3D Immersive Virtual Environments,. In Jan Herrington et al. (Eds.), Proceedings of World Conference on Educational Multimedia, Hypermedia and Telecommunications pp. 159-166, Available at: http://www.editlib.org/p/111949,

[9] Dirkin, K. 2013. Grounding Online Course Design in Bloom's Revised Taxonomy. In Jan Herrington et al. (Eds.), Proceedings of World Conference on Educational Multimedia, Hypermedia and Telecommunications pp. 176-178. Available at http://www.editlib.org/p/111951.

[10] Ford, N. 2000. Cognitive styles and virtual environments. Journal of the American Society for Information Science, 51(6), 543-557.

[11] Honey, P. and Mumford, H. 1992. The Manual of Learning Styles. Maidenhead: Peter Honey.

[12] Huang, T.-H., Liu Y.-C and Chang, H.-C .2012. Learning Achievement in Solving Word-Based Mathematical Questions through a Computer-Assisted Learning System, Journal of Educational Technology \& Society, 15 (1), 248-259.

[13] Kolb, D. A. 1985. Learning style inventory and technical manual. Boston, MA: McBer.

[14] Paek, S., Hoffman, D. L and Black, J. B. 2013. Using Touch-Based Input to Promote Student Math Learning in a Multimedia Learning Environment. In Jan Herrington et al. (Eds.), Proceedings of World Conference on Educational Multimedia, Hypermedia and Telecommunications, pp. 314-323. Available at: http://www.editlib.org/p/111975.

[15] Riding, R. J. 1991. Cognitive styles analysis. Birmingham: Learning and Training Technology.

[16] Riding, R. J. 1997. On the nature of cognitive style. Educational Psychology, 17, 29-50.

[17] Rosenberg, M. J. 2006. Beyond E-Learning: Approaches and Technologies to Enhance Organizational Knowledge, Learning, and Performance. Pfeiffer, 989 Market Street, San Francisco, CA 94103-1741, Available at: www.pfeiffer.com.

[18] Raúl and Fermín 2012. Web 2.0 and Higher Education: Its educational use in the University Environment. In T. Amiel and B. Wilson (Eds.), Proceedings of World Conference on Educational Multimedia, Hypermedia and Telecommunications, pp. 899-904.

[19] Tung-Cheng, H., Ming-Che, L. and Chien-Yuan. S. 2013. Designing and implementing a personalized remedial learning system for enhancing the programming learning,. Educational Technology and Society, 16 (4), $32-46$.

[20] Walker, R. Mace,, D. and Barnes, T. 2013. You Decide: A Novel Multimedia Format for Case Study Assignments in Online and Blended Learning Environments. In Jan Herrington et al. (Eds.), Proceedings of World Conference on Educational 
Multimedia, Hypermedia and Telecommunications $p p$. 427-432. Available at: http://www.editlib.org/p/111993.

[21] Yang, T.-C., Hwang, G.-J. and Yang, S. J.-H. 2013. Development of an adaptive learning system with multiple perspectives based on students' learning styles and cognitive styles. Journal of Educational Technology \& Society, 16 (4), 185-200.

[22] Yasir and Sami, 2011. An approach to Adaptive ELearning Hypermedia System based on Learning Styles (AEHS-LS): Implementation and evaluation. International Journal of Library and Information Science
Vol. 3(1), pp. 15-28. Available at: http://www.academicjournals.org/ijlis.

[23] Tsianos, N., Germanakos, P., Lekkas, Z., Mourlas, C., Belk, M., Christodoulou, E., Spanoudis, G. and Samaras, G. 2008. Enhancing eLearning Environments with Users' Cognitive Factors: The case of EKPAIDEION. Proceedings of the 7th European Conference on e-Learning pp. 877-889. 